\title{
Correction to: Transitions in coping profiles after breast cancer diagnosis: implications for depressive and physical symptoms
}

\section{Jacqueline H. J. Kim ${ }^{1}\left(\mathbb{D} \cdot\right.$ Emma E. Bright ${ }^{1}$.}

Timothy J. Williamson ${ }^{1}\left(\mathbb{D} \cdot\right.$ Jennifer L. Krull $^{1}$.

Karen L. Weihs ${ }^{2}$ Annette L. Stanton ${ }^{1,3,4,5}$

Published online: 14 August 2020

(C) Springer Science+Business Media, LLC, part of Springer Nature 2020

\section{Correction to:}

\section{J Behav Med}

https://doi.org/10.1007/s10865-020-00159-w

Due to publisher processing error, brackets and asterisks noting statistically significant differences in Fig. 3 were omitted. This erratum displays the original author-submitted version of Fig. 3.
Publisher's Note Springer Nature remains neutral with regard to jurisdictional claims in published maps and institutional affiliations.

The original article can be found online at https://doi. org/10.1007/s 10865-020-00159-w.

Jacqueline H. J. Kim

jhjkim@psych.ucla.edu

1 Department of Psychology, University of California (UCLA), Los Angeles, CA, USA

2 Department of Psychiatry, University of Arizona Cancer Center, The University of Arizona, Tucson, AZ, USA

3 UCLA Jonsson Comprehensive Cancer Center, Los Angeles, CA, USA

4 Department of Psychiatry and Biobehavioral Sciences, University of California (UCLA), Los Angeles, CA, USA

5 Cousins Center for Psychoneuroimmunology, Los Angeles, CA, USA 
A

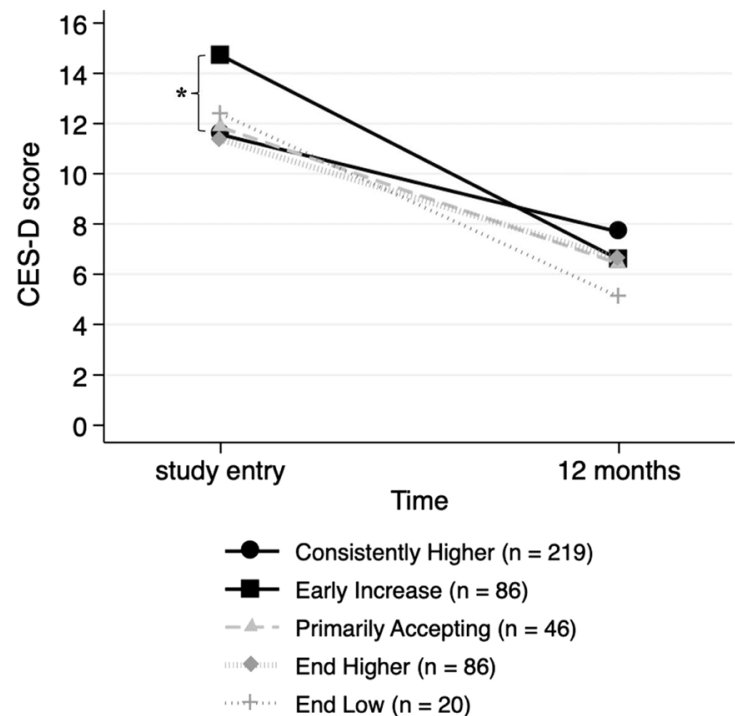

B

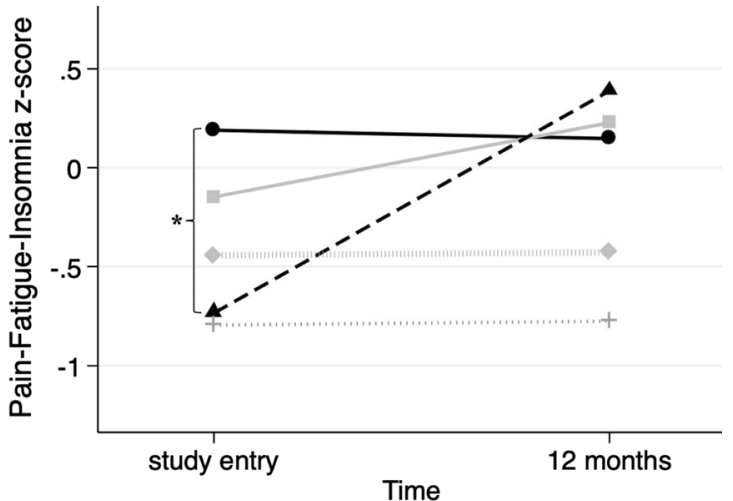

$\longrightarrow$ Consistently Higher ( $n=219$ )

-Early Increase $(n=86)$

- 1 - Primarily Accepting $(n=46)$

End Higher $(n=86)$

....... End Low $(n=20)$

Fig. 3 Predicted depressive (a) and physical (b) symptom scores by coping profile transition type. Note: * $p<.05$ for study entry symptom score; significantly different slopes in black 